\title{
Erratum to: Linear growth faltering in infants is associated with Acidaminococcus sp. and community-level changes in the gut microbiota
}

Ethan K. Gough', David A. Stephens², Erica E.M. Moodie ${ }^{1}$, Andrew J. Prendergast ${ }^{3,4}$, Rebecca J. Stoltzfus ${ }^{5}$, Jean H. Humphrey ${ }^{4,6}$ and Amee R. Manges ${ }^{7^{*}}$

\section{Erratum to:}

After publication of this article [1], the author noticed an error to Fig. 2 (Figure 1 here). The published Figure did not include the links involving the genus Acidaminococcus. The correct version of Fig. 2 (Figure 1 here) is included below.

\footnotetext{
* Correspondence: amee.manges@ubc.ca

${ }^{7}$ Faculty of Medicine, School of Population and Public Health, University of

British Columbia, 137-2206 East Mall, Vancouver V6T 1Z3BC, Canada

Full list of author information is available at the end of the article
} 


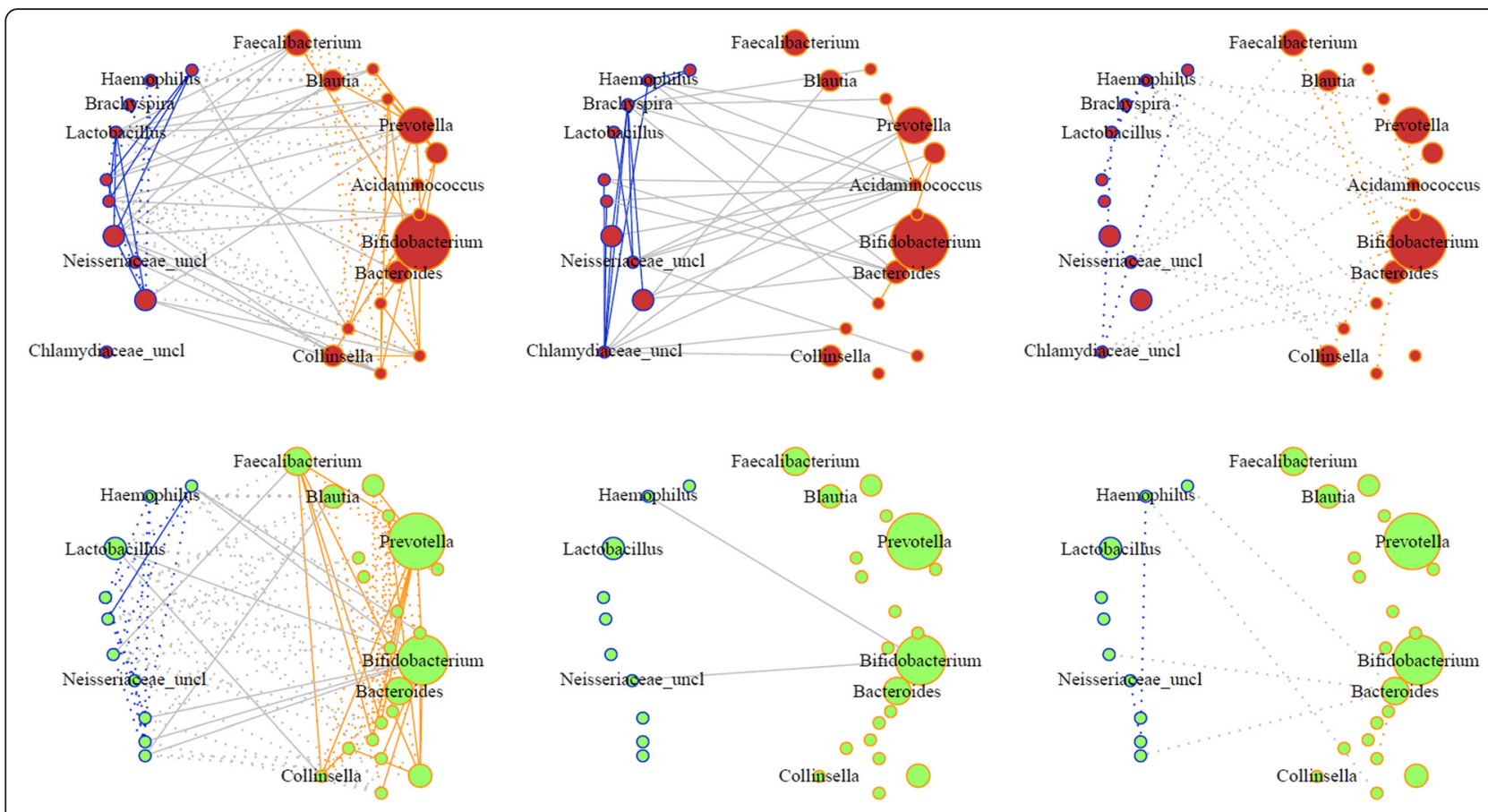

Fig. 1 Graphical models of Malawi case and control microbiota networks constructed using glasso. (Top) Case networks. (Bottom) Control networks. (Left to right) Associations found in both groups, cases only and controls only. Solid and dotted edges indicate

\section{Author details}

'Department of Epidemiology, Biostatistics and Occupational Health, McGill University, Montreal H3A 1A2QC, Canada. ${ }^{2}$ Department of Mathematics and Statistics, McGill University, Montreal H3A 2K6QC, Canada. ${ }^{3}$ Centre for Paediatrics, Blizard Institute, Queen Mary University of London, London E1 2AT, UK. ${ }^{4}$ Zvitambo Institute for Maternal Child Health Research, Harare, Zimbabwe. ${ }^{5}$ Program in International Nutrition, Division of Nutritional Sciences, Cornell University, Ithaca, NY 14853, USA. ${ }^{6}$ Department of International Health, Johns Hopkins Bloomberg School of Public Health, Baltimore, MD 21205, USA. ${ }^{7}$ Faculty of Medicine, School of Population and Public Health, University of British Columbia, 137-2206 East Mall, Vancouver V6T 1Z3BC, Canada.

Received: 18 January 2016 Accepted: 18 January 2016

Published online: 22 January 2016

\section{Reference}

1. Gough EK et al. Linear growth faltering in infants is associated withAcidaminococcus sp. and community-level changes in the gut microbiota. Microbiome. 2015;3:24. doi:10.1186/s40168-015-0089-2.

Submit your next manuscript to BioMed Central and we will help you at every step:

- We accept pre-submission inquiries

- Our selector tool helps you to find the most relevant journal

- We provide round the clock customer support

- Convenient online submission

- Thorough peer review

- Inclusion in PubMed and all major indexing services

- Maximum visibility for your research

Submit your manuscript at www.biomedcentral.com/submit
Biomed Central 